\title{
WHITE SPACE STEGANOGRAPHY ON TEXT BY USING LZW-HUFFMAN DOUBLE COMPRESSION
}

\author{
Gelar Budiman and Ledya Novamizanti \\ Electrical Engineering Faculty, Telkom University, Bandung, Indonesia.
}

\begin{abstract}
Privacy, especially in a cellphone, is an important thing and should be protected. Steganography is a method used to protect a sensitive information. The issue tried to be discussed in this study is the issue on inserting technique in a text through a simple method of White Space Steganography on android. The inserted message has been compressed through a double compression method by using LZW and Huffman so that the size of message to be inserted can be minimized while the capacity of the inserted message can be minimized. The compression shows that the compression ratio much depends on the type of text input to the text to be sent; the more the repetition or duplication found on the message, the smaller the compression ratio will be. The compression process using Android based smartphone is relatively fast with the average duration of 0.045 seconds, either for the insertion or extraction.
\end{abstract}

\section{KEYWORDS}

White Space Steganography, teks, android, compression, LZW, Huffman Coding

\section{INTRODUCTION}

Difficulties in protecting one's privacy is getting challenging along with the development in digital communication technology. One of the popular communication technologies that consistently develops is cellphone, particularly android. Cellphone is often used as a medium to save and send sensitive information. As cell phone is an accessible device, the protection towards sensitive information within the cellphone becomes essential.

One of the methods that can be taken as to protect the information is by using steganography, i.e. a technique to hide information by inserting a message into another message $\mathrm{e}^{[4]}$, so that it is only the intended person who will aware about the message. One of the recent studies on steganography is the one conducted by Ratna E. and V.K. Govindan, i.e. the unlimited payload steganography ${ }^{[4]}$. However, the study on LZW and Huffman compression has also been conducted, as that one of Linawati and Henry P. Panggabean ${ }^{[6]}$. Compression is usually conducted on the watermarking technique towards cover image after the inserting process is taken, as conducted by Dr. Ajit Singh and Meenakshi Gahlawat ${ }^{[9]}$. Meanwhile, all of the studies have not been implemented on android.

In this study, double compression will be conducted by using LZW-Huffman technique on textual data which is then hidden through white space steganography. The system will then be implemented on android. By using LZW and Huffman techniques on the compression process, it is hoped that the capacity of the hidden textual data can be bigger than the previous study. 


\section{THEORETICAL BACKGROUND}

\subsection{White Space Steganography}

Steganography is derived from Greek-Steganós which means hide and Graptos which means writing - that in general it can be defined as hidden writing ${ }^{[7]}$. In general, steganography is an art and knowledge in hiding a message into a medium in a way that it is only the sender and the receiver who know or realize that there is actually a secret message ${ }^{[10]}$.

Steganography in digital era has been much developed. The media that can be used for steganography are text, picture, audio, and video. One of the simple media that can be used is steganography on texts through White Space Steganography method. White Space Steganography is a simple steganography method by using "space" and "tab" characters as to show hidden message bits. "Space" and "tab" can be used since it is difficult to recognize and is not reflected in text viewer.

\subsection{LZW Compression Method}

The storage of big size data or files takes up a big storage capacity. Pertaining to this, compression technique can be used to minimize the data size. Compression is a process in encrypting a group of data into a code as to optimize the storage space, as well as the transmission time $^{[3]}$.

Lossless compression method is data compression method which can generate data identical to the original one, i.e. by reconstructing the compressed data ${ }^{[1]}$. One of the examples of lossless compression is by using LZW algorithm.

LZW (Lempel Zev Welch) algorithm is developed by using compression method developped by Ziv and Lempel in 1977. This algorithm carries out the lossless compression by using dictionary, where the text fragments are replaced by the index derived from a "dictionary". Character String is replaced by table code created for each string coming. Table is made for the input reference for the upcoming string ${ }^{[4]}$.

The whole LZW compression algorithm is as follow:

1) Dictionary is initialized by all basic existing characters : \{'A'..'Z','a'..'z','0'..'9'\}.

2) $P \leftarrow$ the first character in character stream.

3) $C \leftarrow$ the upcoming character in characterstream.

4) Isstring $(P+C)$ found in dictionary?

- If yes, so $P \leftarrow P+C$ (combine $P$ and $C$ into a new string).

- If not, so :

i. Output a code to replace string P.

ii. Add string $(\mathrm{P}+\mathrm{C})$ into dictionary and give the next number/code that has not been used indictionary to the string.

iii. $P \leftarrow C$.

5) Is there still any upcoming character remained in character stream ?

- If yes, return to step 2.

- If not,output the code that will replace string $P$, and terminate the process (stop). 
The decompression process in LZW is conducted through the principles similar to those in compression process. In the beginning dictionary is initialized by all existing basic characters. In each step, the code is then read one by one from code stream and taken from string in dictionary which corresponds to the code. A new string is then added into dictionary. The following is the full decompression process:

1) Dictionary is initialized by all the existing characters : \{'A'..'Z','a'..' $z$ ', 'O'..'9'\}.

2) $C W \leftarrow$ the first code stream (referring to one of the basic characters).

3) Consult dictionary and output string of the code (string.CW) into character stream.

4) $P W \leftarrow C W ; C W \leftarrow$ the upcoming code ofcode stream.

5) Is string. $C W$ found in dictionary?

- If yes, then :

i. output string. $C W$ to character stream

ii. $P \leftarrow$ string. $P W$

iii. $C \leftarrow$ the first character of string. $C W$

iv. Add string $(P+C)$ into dictionary

- If not, then :

i. $P \leftarrow$ string. $P W$

ii. $C \longleftarrow$ the first character of string. $P W$

iii. output string $(P+C)$ into character stream and add the string into dictionary(it finally can correspond with $C W$ );

6) Is there any other code in code stream?

- If yes, back to the step 4 .

- If no, terminate the process (stop).

\subsection{Huffman Compression Method ${ }^{[2]}$}

Huffman coding is a popular method for data compression. It serves as the basis for several popular programs run on various platforms. Some programs use just the Huffman method, while others use it as one step in a multistep compression process. The Huffman method generally produces better codes when the probabilities of the symbols are negative powers of 2 . Huffman constructs a code tree from the bottom up (builds the codes from right to left). Since its development, in 1952, by D. Huffman, this method has been the subject of intensive research into data compression.

The algorithm starts by building a list of all the alphabet symbols in descending order of their probabilities. It then constructs a tree, with a symbol at every leaf, from the bottom up. This is done in steps, where at each step the two symbols with smallest probabilities are selected, added to the top of the partial tree, deleted from the list, and replaced with an auxiliary symbol representing the two original symbols. When the list is reduced to just one auxiliary symbol (representing the entire alphabet), the tree is complete. The tree is then traversed to determine the codes of the symbols.

\section{SYSTEM DESIGN}

\subsection{Analysis and Design}

Problem to be studied is the insertion technique on text by using a simple method of White Space Steganography. The message inserted has been compressed by using a double compression method of LZW and Huffman so that the size of the message is smaller and the capacity of the inserted message is bigger. 


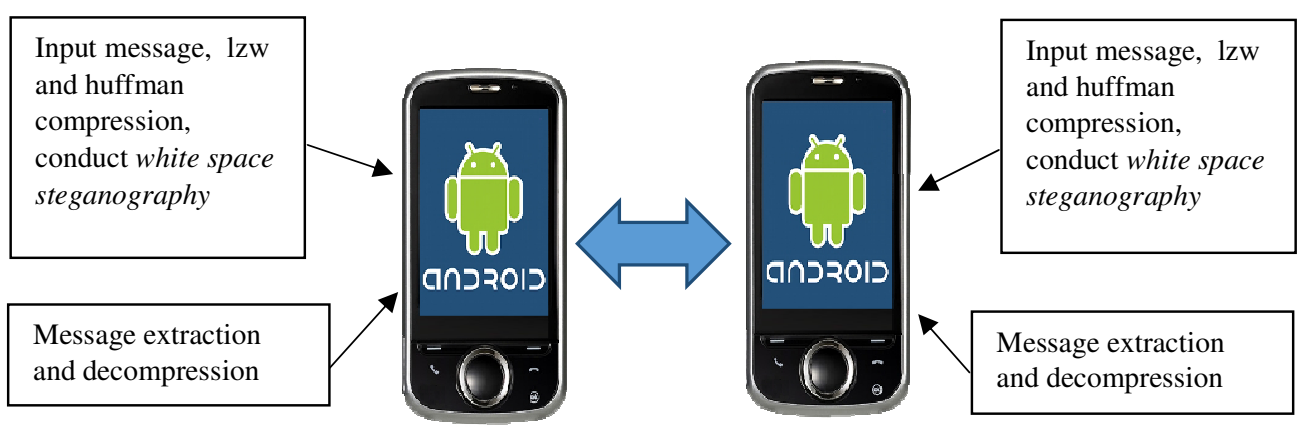

Figure 2 General Model of the System

\subsection{System Flow Chart}
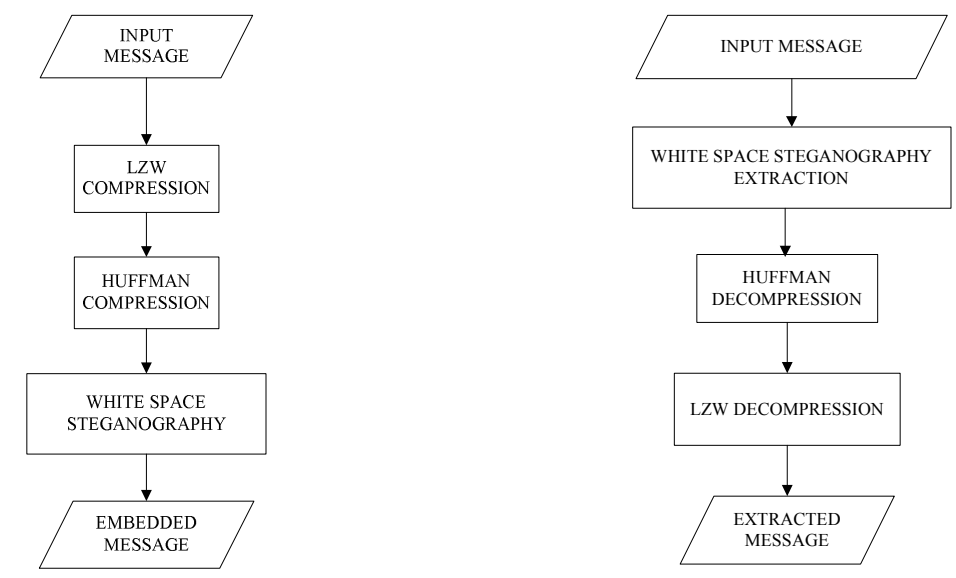

Figure 3 Flow Chart of the Compression-Embedding and Decompression-Extraction Process

The message input is a text used as the secret message that will be inserted into white space steganography. The text input should be in the list of LZW dictionary, if not, there will be a warning to reinput the text. The input text will then be compressed by using LZW (Lempel Zev Welch) technique. LZW technique uses dictionary as its reference. LZW priorinitial dictionary consists of 66 initial dictionaries comprising the characters usually used, which can be developed into 128 dictionaries. The 128 dictionaries are used to get a maximum result in the upcoming Huffman compresion. Table 1 in the appendix shows the prior initials of the LZW dictionary.

LZW compression results in the numbers representing dictionary index used. LZW dictionary has a range of 0 and 127 where each numbers requires the number of bits as to represent it. The numbers have been compressed by using Huffman algorithm with a static Huffman tree table which has been determined previously. Static tree table is used if it is difficult for the receivers to redecompress the steganography message by using adaptive tree table as they do not have 
the adaptive tree table. Table2 in appendix shows the example of Huffman tree table used with different probability of occurrence of LZW dictionary index.

The Huffman compression results in representation bits. These bits will be inserted into the cover text by altering bit ' 1 ' into 'Tab' and ' 0 ' into 'space'. By using Tab and space characters, the message can be difficult to be recognized. The message output comprises the text cover along with the result fromwhite space steganography. The text output will be reproceeded as to obtain the secret message inserted previously. The text cover and the inserted message using 'tab' and 'space' included in the message generated from steganography will be separated first.

The white space steganography extraction process is quite simple, i.e. by changing the 'Tab' character into bit ' 1 ' and 'Space' character into bit ' 0 '. Huffman decompression is same with the one used in the compression by using static Huffman tree table which has been determined previously. Since it uses static Huffman tree table, the receiver is not required to ask the huffman table to the sender since the static tree table is included in the program. LZW decompression process is conducted by adapting the adaptive dictionary so that the inserted secret message can be generated.

\section{APPLICATION PERFORMANCE ANALYSIS}

The test in the study is aimed at:

1. Finding out the sytem perfomance in the form of compression ratio

2. Finding out the system performance in accordance with the compression and decompression time.

3. Finding out and analyzing the system performance towards different inputs

\subsection{Test Setting}

The test is taken to be set on android smartphone Samsung S Advance device, with the following specification :

1) Processor Dual Core $800 \mathrm{MHz}$.

2) Internal Memory: 4 GB Storage.

3) RAM $768 \mathrm{MB}$

4) External Memory: $16 \mathrm{~GB}$

5) OS Android 2.3 Gingerbread.

6) PLS TFT capacitive touchscreen, $16 \mathrm{M}$ colors ( $480 \times 800$ pixels, 3.8 inches ( 246 ppi pixel density))

Message input to be inserted are comprised by different input samples as can be seen in table 3 in appendix. The scenario used in the test is as follow:

1. Testing the compression calculation by using the manual calculation and comparing it by using the program made.

2. Measuring the compression ratio of the message input with different sum of characters and symbols.

3. Measuring the time used in the compression and decompression 
Parameters used in the application test are compression time and compression ratio. The process time is an important factor in compresion and decompression process. Ratio in percentage is calculated using the following equation ${ }^{[5]}$ :

$$
\text { Ratio }=(\text { original file size }- \text { compressed file size }) / \text { initial size } * 100 \%
$$

\subsection{Test Result}

\subsubsection{Test on the Compression Ratio Manual Calculation and the Calculation using Program}

The following is the explanation on the compression result obtained from the manual calculation compared with the calculation using program. Meanwhile, the LZW compression process with that input can be seen in table 4 in appendix. The dictionary index generated from LZW compression will be compressed by using Huffman compression with static tree table.

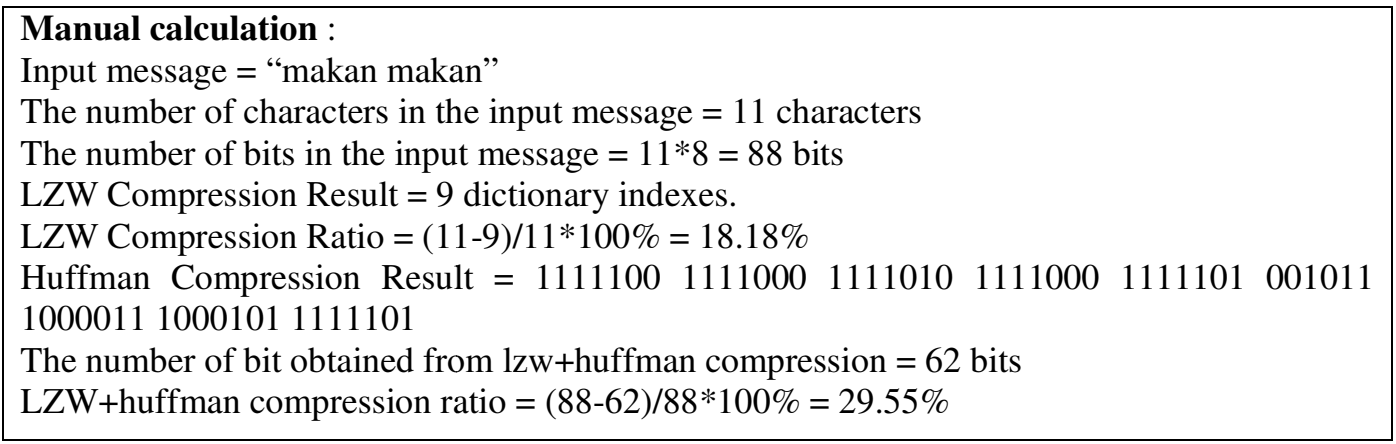

The test result on the program showing the application interface can be seen in figure 4 .

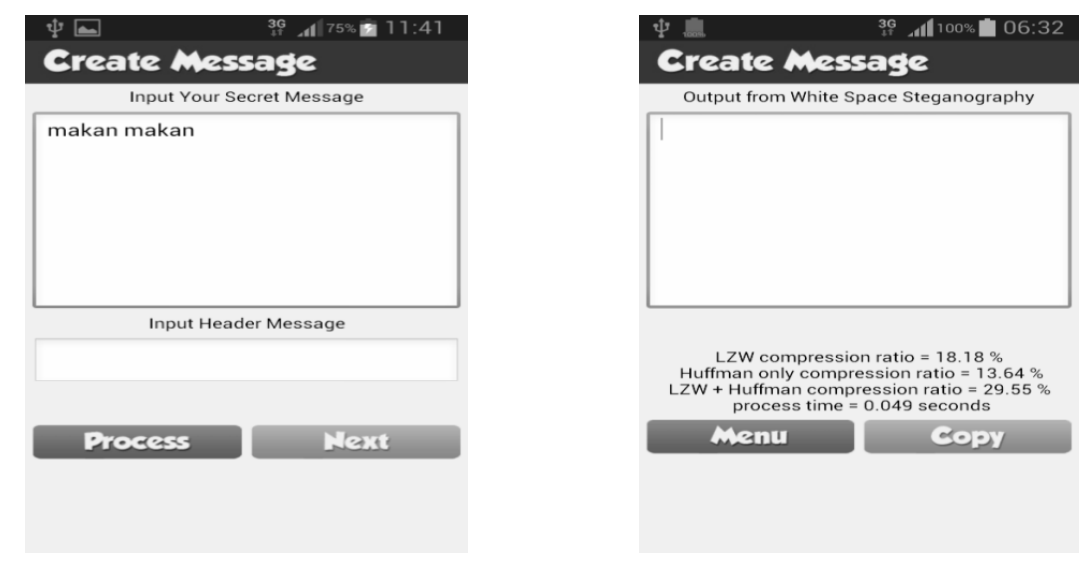

Figure 4 The application interface on the test of input compression and the decompression result

It can be seen that the LZW compression ratio is $18.18 \%$ and the Huffman+LZW ratio is $29.55 \%$. It means that the result generated from the program is same withthat one resulted from the manual calculation. 


\subsubsection{Compression Ratio}

The test is taken with ratio of the number character with input message symbol number 0 . Table 5 in appendix shows compression ratio as the test result on several processes conducted in the implemented system. Table 5 can be presented in the analysis graphic as can be seen in figure 5 .

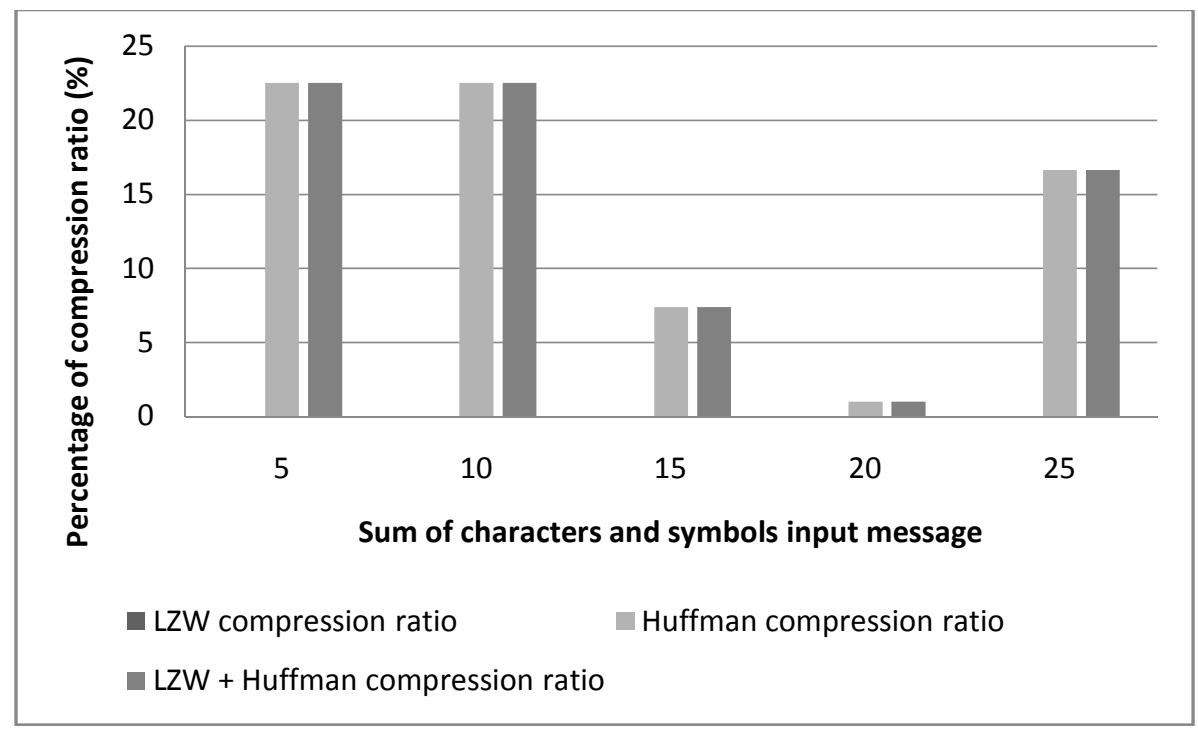

Figure 5 Graph of Compression Ratio of Input Message with Difference in Sum of Characters and Symbol 0

The test above shows that the number of characters and symbol is equal that causes no repeating character pair defined that causes LZW compression ratio of 1:1. The scenario above shows that it is only Huffman compression that works, where the compression ratio will increase if the input message character has a small bit representation in static Huffman tree table. A non letter symbol has a big bit representation so that the ratio is small.

The following test is the test on the differenceof the input message of 30 characters that has different total number of symbols. The test can be seen in table 6 in appendix. Table 6 can be summarized into the graphs in Figure 6. 


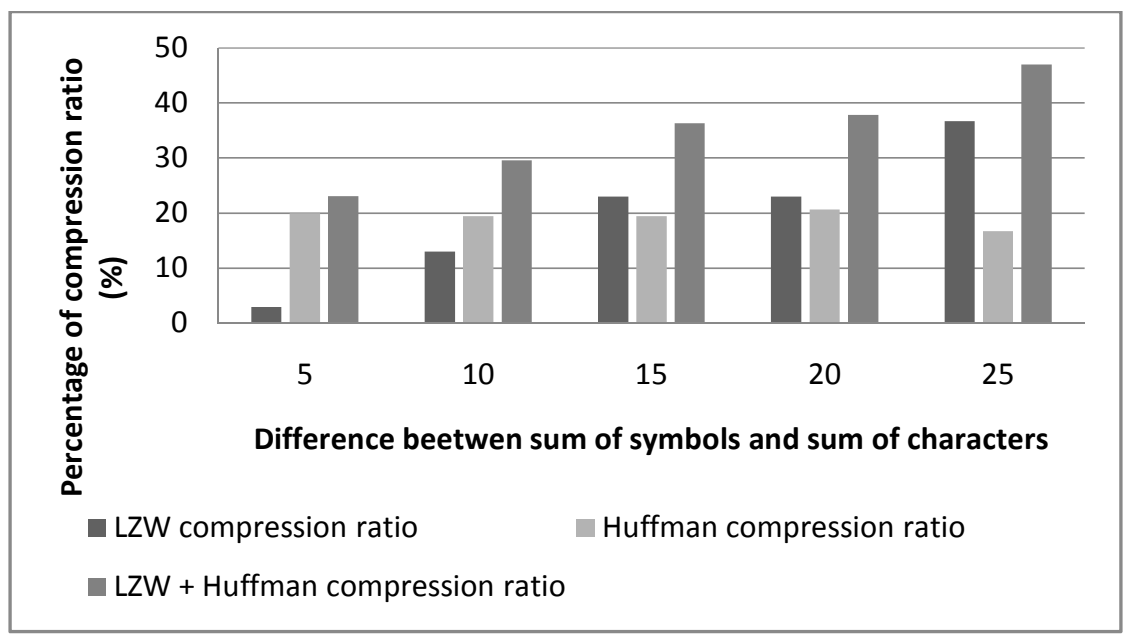

Figure6Graphs of compression ratio with the input message of 30 characters and variousdifference of the sum of characters and symbols

From the test, it can be seen that with the same total number of characters, the bigger difference in the sum of character and the sum of symbol, the bigger LZW+ Huffman will be. It is because that big difference means that there are many repeating symbols and as a consequence, LZW compression is getting better. Unfortunately,Huffman compression ratio is getting smaller if there are many repeating high bit symbols. However, LZW compression value will exceed the Huffman compression if the repeating symbols are found more, which also means that even if the difference is getting bigger, the Huffman+LZWdouble compresion ratio is still better.

The following test is the test using input message with repeating character pair. The test process can be seen in table 7 in the appendix. From the table, it can be concluded in the graphs in figure 7.

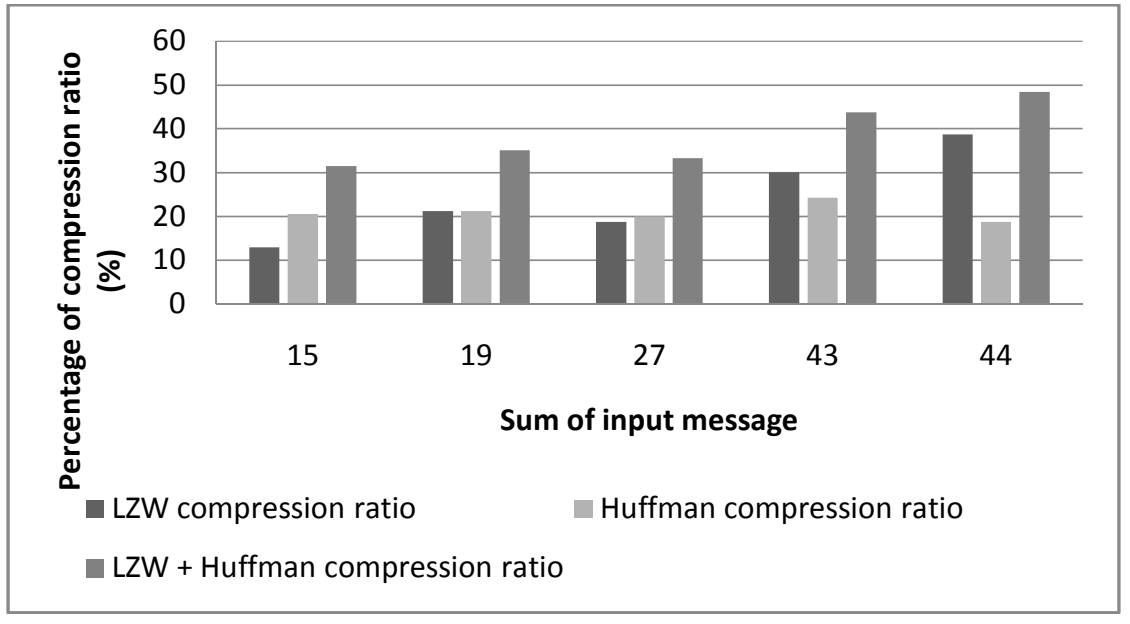

Figure7Graphs of compression ratio with the input message that has repeating character pairs and different sum of input message 
The test shows that the Huffman+LZW double compression ratio is getting bigger if the number of input characters as well as the number of repeating character pairsare also getting bigger. It is influenced by the LZW compression which is getting better if the number of repeating characters is increasing. Meanwhile, for Huffman, the size of compression depends on the number of bit given for each character.

\subsubsection{Process Time}

Table 8 in the appendix is the result of process time used as to create and read messages involving 20 samples. However, figure 8 shows the visualization in accordance with table 8 .

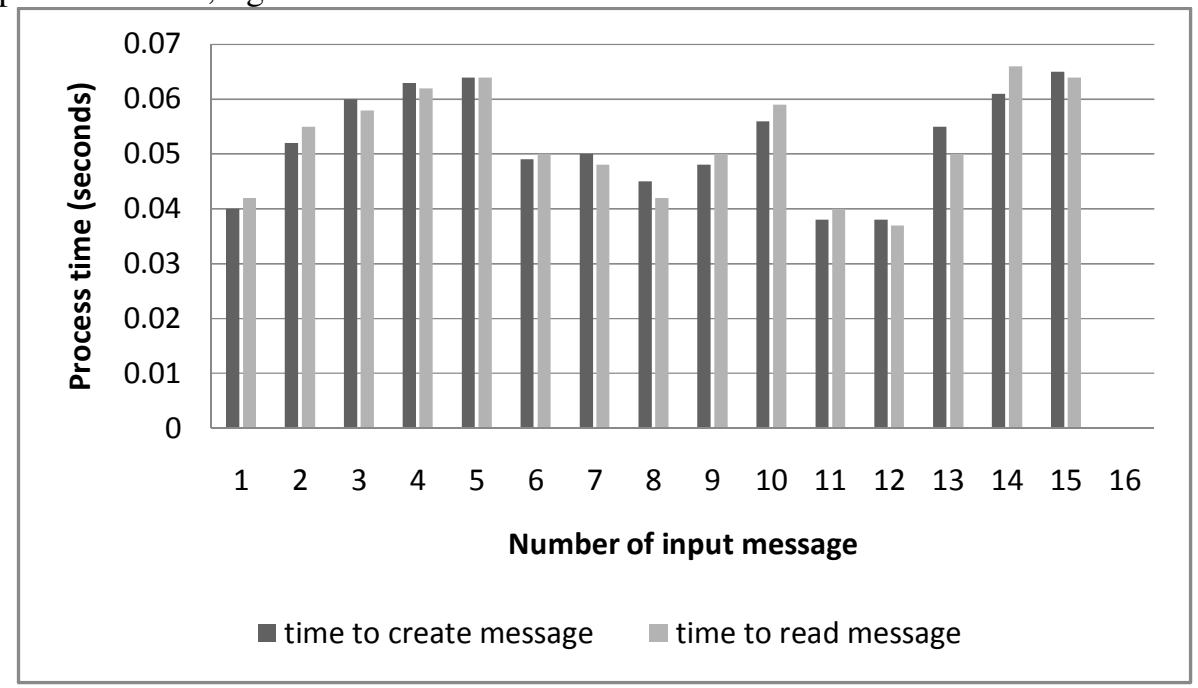

Figure8 Process time result

The process time used is almost same for all the tests conducted since all of the tests have a similar process. However, the input message with more characters requires a longer time. The process time cannot be separated from thehardware used in the experiment.

\section{CONCLUSION AND RECOMMENDATION}

\subsection{Conclusion}

Based on the implementation of steganography of text using double compression with LZWHuffman, it can be concluded that:

1. From the compression ratio obtained, it can be seen that the system is able to produce different ratio depending on the input used. If the message input consisting of several repeating character pairs, the compression ratio will be big. If the input message involves few repeating words, the compression ratio will be smaller due to the LZW compression algorithm. If the input message is only comprised by symbol, instead of letter, the compression ratio will be small since in the static huffman tree table, the bit for non letter character is represented to be big and the compression ratio will be big if the input message comprises many letter characters.

2. The speed in the process time as to generate text stego is relatively fast and the influence of the input that has many repeating words as well as the one that has few repeating words is 
International Journal of Computer Networks \& Communications (IJCNC) Vol.7, No.2, March 2015

not much different. The process time tocreate messageandto read messageis not much different.

\subsection{Recommendation}

1. Instead of text, picture or sound can also be usedas the media in steganography, i.e. as to ensure a higher security level.

2. Other compression algorithm can also be used as to get a proper compression ratio.

\section{REFFERENCE}

[1] Deorowicz, Sebastian.20013. Universal Lossless Data Compression Algorithms. Gliwice:Silesian University of Technology

[2] D. Salomon. Data Compression: The Complete Reference. Springer, 1998.

[3] Howe, D. Free Online Dictionary of Computing, http://www.foldoc.org/

[4] Kanikar, Prashasti, Ratnesh N. Chaturvedi dan Vibhishek Kashyap. 2013. Image Steganography using DCT, DST, Haar and Walsh Transform. International Journal of Computer Applications, Vol. 65, No. 17, Hal. 34-37.

[5] Khalid Sayood, Introduction to Data Compression, Academic Press, 2000.

[6] Linawati dan Henry P. Panggabean. 2004, Perbandingan Kinerja Algoritma Kompresi Huffman, Lzw, dan Dmc pada Berbagai Tipe File. Integral, Vol. 9, No. 1, 2004, hal 14-15

[7] Nosrati, Masoud., RonakKarimidan Mehdi Hariri.2011. An Introduction to Steganography Methods. World Applied Programming, Vol 1, No 3, 191-195, Agustus 2011

[8] Safaat, Nazruddin.2012. Pemrograman Aplikasi Mobile Smartphone dan Tablet PC Berbasis Android. Bandung : Informatika

[9] Singh, Dr. Ajit dan Meenakshi Gahlawat. 2013. Secure Data Transmission using Watermarking and Image Compression. International Journal of Advanced Research in Computer Engineering \& Technology, Vol. 2, No.5, Hal. 1709-1715.

[10] Saleh Saraireh. 2013. A Secure Data Communication System Using Cryptography and Steganography. International Journal of Computer Networks \& Communications (IJCNC) Vol. 5 No. 3, May 2013.

\section{APPENDIX}

Table 1Prior Initials of LZW Dictionary

\begin{tabular}{|c|c|c|c|c|c|c|c|}
\hline Index & Dictionary & Index & Dictionary & Index & Dictionary & Index & Dictionary \\
\hline 0 & $\mathrm{a}$ & 17 & $\mathrm{R}$ & 34 & 7 & 51 & $:$ \\
\hline 1 & $\mathrm{~b}$ & 18 & $\mathrm{~S}$ & 35 & 8 & 52 & $;$ \\
\hline 2 & $\mathrm{c}$ & 19 & $\mathrm{~T}$ & 36 & 9 & 53 & , \\
\hline 3 & $\mathrm{~d}$ & 20 & $\mathrm{U}$ & 37 & @ & 54 &. \\
\hline 4 & $\mathrm{e}$ & 21 & $\mathrm{~V}$ & 38 & $\#$ & 55 & $=$ \\
\hline 5 & $\mathrm{f}$ & 22 & $\mathrm{~W}$ & 39 & $\%$ & 56 & - \\
\hline 6 & $\mathrm{~g}$ & 23 & $\mathrm{X}$ & 40 & $\&$ & 57 & $<$ \\
\hline 7 & $\mathrm{~h}$ & 24 & $\mathrm{y}$ & 41 & $*$ & 58 & $>$ \\
\hline 8 & $\mathrm{i}$ & 25 & $\mathrm{z}$ & 42 & $/$ & 59 & \{ \\
\hline 9 & $\mathrm{j}$ & 26 & $(\mathrm{spasi})$ & 43 & - & 60 & \} \\
\hline 10 & $\mathrm{k}$ & 27 & 0 & 44 & + & 61 & {[} \\
\hline 11 & $\mathrm{l}$ & 28 & 1 & 45 & ( & 62 & ] \\
\hline 12 & $\mathrm{~m}$ & 29 & 2 & 46 & ) & 63 & । \\
\hline 13 & $\mathrm{n}$ & 30 & 3 & 47 & $?$ & 64 & $\wedge$ \\
\hline 14 & $\mathrm{o}$ & 31 & 4 & 48 & $!$ & 65 & $\$$ \\
\hline 15 & $\mathrm{p}$ & 32 & 5 & 49 & $\cdots$ & & \\
\hline 16 & $\mathrm{q}$ & 33 & 6 & 50 & & & \\
\hline
\end{tabular}


International Journal of Computer Networks \& Communications (IJCNC) Vol.7, No.2, March 2015

Table 2 Huffman Tree

\begin{tabular}{|c|c|c|c|c|c|}
\hline $\begin{array}{c}\text { Index of } \\
\text { LZW } \\
\text { Dictionary }\end{array}$ & Probability & Huffman Bit & $\begin{array}{c}\text { Index of LZW } \\
\text { Dictionary }\end{array}$ & Probability & Huffman Bit \\
\hline 0 & 0.0234375 & 1111000 & 64 & 0.0078125 & 11101111 \\
\hline 1 & 0.0234375 & 1111001 & 65 & 0.0078125 & 0100110 \\
\hline 2 & 0.0234375 & 000100 & 66 & 0.015625 & 1000011 \\
\hline 3 & 0.0234375 & 001100 & 67 & 0.015625 & 1000100 \\
\hline 4 & 0.0234375 & 001101 & 68 & 0.015625 & 1000101 \\
\hline 5 & 0.0234375 & 001110 & 69 & 0.015625 & 1000110 \\
\hline 6 & 0.0234375 & 001111 & 70 & 0.015625 & 1000111 \\
\hline 7 & 0.0234375 & 010000 & 71 & 0.015625 & 1001000 \\
\hline 8 & 0.0234375 & 010001 & 72 & 0.015625 & 1001001 \\
\hline 9 & 0.0234375 & 010010 & 73 & 0.015625 & 1001010 \\
\hline 10 & 0.0234375 & 1111010 & 74 & 0.015625 & 1001011 \\
\hline 11 & 0.0234375 & 1111011 & 75 & 0.015625 & 1001100 \\
\hline 12 & 0.0234375 & 1111100 & 76 & 0.015625 & 1001101 \\
\hline 13 & 0.0234375 & 1111101 & 77 & 0.015625 & 1001110 \\
\hline 14 & 0.0234375 & 1111110 & 78 & 0.015625 & 1001111 \\
\hline 15 & 0.0234375 & 1111111 & 79 & 0.015625 & 1010000 \\
\hline 16 & 0.0234375 & 000000 & 80 & 0.015625 & 1010001 \\
\hline 17 & 0.0234375 & 000001 & 81 & 0.015625 & 1010010 \\
\hline 18 & 0.0234375 & 000010 & 82 & 0.015625 & 1010011 \\
\hline 19 & 0.0234375 & 000011 & 83 & 0.015625 & 1010100 \\
\hline 20 & 0.0234375 & 000101 & 84 & 0.015625 & 1010101 \\
\hline 21 & 0.0234375 & 000110 & 85 & 0.015625 & 1010110 \\
\hline 22 & 0.0234375 & 000111 & 86 & 0.015625 & 1010111 \\
\hline 23 & 0.0234375 & 001000 & 87 & 0.015625 & 1011000 \\
\hline 24 & 0.0234375 & 001001 & 88 & 0.015625 & 1011001 \\
\hline 25 & 0.0234375 & 001010 & 89 & 0.015625 & 1011010 \\
\hline 26 & 0.0234375 & 001011 & 90 & 0.015625 & 1011011 \\
\hline 27 & 0.0078125 & 11001010 & 91 & 0.015625 & 1011100 \\
\hline 28 & 0.0078125 & 11001011 & 92 & 0.015625 & 1011101 \\
\hline 29 & 0.0078125 & 11001100 & 93 & 0.015625 & 1011110 \\
\hline 30 & 0.0078125 & 11001101 & 94 & 0.015625 & 1011111 \\
\hline 31 & 0.0078125 & 11001110 & 95 & 0.015625 & 1100000 \\
\hline 32 & 0.0078125 & 11001111 & 96 & 0.015625 & 1100001 \\
\hline 33 & 0.0078125 & 11010000 & 97 & 0.015625 & 1100010 \\
\hline 34 & 0.0078125 & 11010001 & 98 & 0.015625 & 1100011 \\
\hline 35 & 0.0078125 & 11010010 & 99 & 0.015625 & 1100100 \\
\hline 36 & 0.0078125 & 11010011 & 100 & 0.015625 & 0100111 \\
\hline 37 & 0.0078125 & 11010100 & 101 & 0.015625 & 0101000 \\
\hline 38 & 0.0078125 & 11010101 & 102 & 0.015625 & 0101001 \\
\hline 39 & 0.0078125 & 11010110 & 103 & 0.015625 & 0101010 \\
\hline 40 & 0.0078125 & 11010111 & 104 & 0.015625 & 0101011 \\
\hline 41 & 0.0078125 & 11011000 & 105 & 0.015625 & 0101100 \\
\hline 42 & 0.0078125 & 11011001 & 106 & 0.015625 & 0101101 \\
\hline 43 & 0.0078125 & 11011010 & 107 & 0.015625 & 0101110 \\
\hline 44 & 0.0078125 & 11011011 & 108 & 0.015625 & 0101111 \\
\hline 45 & 0.0078125 & 11011100 & 109 & 0.015625 & 0110000 \\
\hline 46 & 0.0078125 & 11011101 & 110 & 0.015625 & 0110001 \\
\hline 47 & 0.0078125 & 11011110 & 111 & 0.015625 & 0110010 \\
\hline 48 & 0.0078125 & 11011111 & 112 & 0.015625 & 0110011 \\
\hline 49 & 0.0078125 & 11100000 & 113 & 0.015625 & 0110100 \\
\hline
\end{tabular}


International Journal of Computer Networks \& Communications (IJCNC) Vol.7, No.2, March 2015

\begin{tabular}{|l|l|l|l|l|l|}
\hline 50 & 0.0078125 & 11100001 & 114 & 0.015625 & 0110101 \\
\hline 51 & 0.0078125 & 11100010 & 115 & 0.015625 & 0110110 \\
\hline 52 & 0.0078125 & 11100011 & 116 & 0.015625 & 0110111 \\
\hline 53 & 0.0078125 & 11100100 & 117 & 0.015625 & 0111000 \\
\hline 54 & 0.0078125 & 11100101 & 118 & 0.015625 & 0111001 \\
\hline 55 & 0.0078125 & 11100110 & 119 & 0.015625 & 0111010 \\
\hline 56 & 0.0078125 & 11100111 & 120 & 0.015625 & 0111011 \\
\hline 57 & 0.0078125 & 11101000 & 121 & 0.015625 & 0111100 \\
\hline 58 & 0.0078125 & 11101001 & 122 & 0.015625 & 0111101 \\
\hline 59 & 0.0078125 & 11101010 & 123 & 0.015625 & 011110 \\
\hline 60 & 0.0078125 & 11101011 & 124 & 0.015625 & 011111 \\
\hline 61 & 0.0078125 & 11101100 & 125 & 0.015625 & 1000000 \\
\hline 62 & 0.0078125 & 11101101 & 126 & 0.015625 & 1000001 \\
\hline 63 & 0.0078125 & 11101110 & 127 & 0.015625 & 1000010 \\
\hline
\end{tabular}

Table 3 Samples of input message

\begin{tabular}{|c|l|}
\hline No & \\
\hline 1 & Detik \\
\hline 2 & Abcdefghij \\
\hline 3 & detik0123456789 \\
\hline 4 & $! @ \# \$ \% \wedge \& *()_{-}-+=: ;,<>$ \\
\hline 5 & abcdefghijklmnopqrst!@\#\$\% \\
\hline 6 & aabbbbcdefghijklmnopqrstuvwxy \\
\hline 7 & aaaabcbcbcddddefghijklmnopqrst \\
\hline 8 & aaaabcccdefffefgefghijklmnoooo \\
\hline 9 & aaabbabccbcbbbcddeefghijjjjjjj \\
\hline 10 & abababababcdceabcdedeaaaaaaabc \\
\hline 11 & ular lari lurus \\
\hline 12 & saya suka susu sapi \\
\hline 13 & eleven benevolent elephants \\
\hline 14 & freezy breeze made these three trees freeze \\
\hline 15 & can you can a can as a canner can can a can? \\
\hline
\end{tabular}

Table 4 LZW compression process

\begin{tabular}{|c|c|c|c|c|}
\hline Step & Position & Character & New Dictionary & Output \\
\hline 1 & 1 & $\mathrm{M}$ & {$[66] \mathrm{ma}$} & {$[12]$} \\
\hline 2 & 2 & $\mathrm{~A}$ & {$[67] \mathrm{ak}$} & {$[0]$} \\
\hline 3 & 3 & $\mathrm{~K}$ & {$[68] \mathrm{ka}$} & {$[10]$} \\
\hline 4 & 4 & $\mathrm{~A}$ & {$[69] \mathrm{an}$} & {$[0]$} \\
\hline 5 & 5 & $\mathrm{n}$ & {$[70] \mathrm{n}(\mathrm{spasil})$} & {$[13]$} \\
\hline 6 & 6 & (spasi) & {$[71](\mathrm{spasi}) \mathrm{m}$} & {$[66]$} \\
\hline 7 & 7 & $\mathrm{ma}$ & {$[72] \mathrm{mak}$} & {$[68]$} \\
\hline 8 & 9 & $\mathrm{Ka}$ & {$[73] \mathrm{kan}$} & {$[13]$} \\
\hline 9 & 11 & $\mathrm{~N}$ & - & {$[6]$} \\
\hline
\end{tabular}


International Journal of Computer Networks \& Communications (IJCNC) Vol.7, No.2, March 2015

Table 5 Compression Ratio of input message with different in the sum of character and symbol 0

\begin{tabular}{|c|c|c|c|c|c|c|}
\hline Input Message & $\begin{array}{c}\text { Sum of } \\
\text { Characters }\end{array}$ & $\begin{array}{l}\text { Sum of } \\
\text { Symbols }\end{array}$ & $\begin{array}{c}\text { Differenc } \\
\mathrm{e}\end{array}$ & \begin{tabular}{|c|} 
LZW \\
Compressio \\
n Ratio $(\%)$
\end{tabular} & \begin{tabular}{|c|} 
Huffman \\
Compression \\
Ratio $(\%)$
\end{tabular} & $\begin{array}{c}\text { LZW + } \\
\text { Huffman } \\
\text { Compression } \\
\text { Ratio }(\%) \\
\end{array}$ \\
\hline detik & 5 & 5 & 0 & 0 & 22,5 & 22,5 \\
\hline abcdefghij & 10 & 10 & 0 & 0 & 22,5 & 22,5 \\
\hline detik0123456789 & 15 & 15 & 0 & 0 & 7,4 & 7,4 \\
\hline $\begin{array}{l}! @ \# \$ \% \wedge \& *()_{-} \\
+=: ;, .<>\end{array}$ & 20 & 20 & 0 & 0 & 1 & 1 \\
\hline $\begin{array}{l}\text { abcdefghijklmnopqrst } \\
\text { !@\#\$\% }\end{array}$ & 25 & 25 & 0 & 0 & 16,67 & 16,67 \\
\hline
\end{tabular}

Table6 Compression Ratio of input message with the sum of characters of three and different sum of symbols

\begin{tabular}{|l|c|c|c|c|c|c|}
\hline \multicolumn{1}{|c|}{ Input Message } & $\begin{array}{c}\text { Sum of } \\
\text { Characters }\end{array}$ & $\begin{array}{c}\text { Sum of } \\
\text { Symbols }\end{array}$ & $\begin{array}{c}\text { Differenc } \\
\mathrm{e}\end{array}$ & $\begin{array}{c}\text { LZW } \\
\text { Compressio } \\
\text { n Ratio(\%) }\end{array}$ & $\begin{array}{c}\text { Huffman } \\
\text { Compression } \\
\text { Ratio (\%) }\end{array}$ & $\begin{array}{c}\text { LZW + } \\
\text { Huffman } \\
\text { Compression } \\
\text { Ratio (\%) }\end{array}$ \\
\hline $\begin{array}{l}\text { aabbbbcdefghijklmno } \\
\text { pqrstuvwxy }\end{array}$ & 30 & 25 & 5 & 2.9 & 20 & 23.07 \\
\hline $\begin{array}{l}\text { aaaabcbcbcddddefghi } \\
\text { jklmnopqrst }\end{array}$ & 30 & 20 & 10 & 13 & 19.4 & 29.6 \\
\hline $\begin{array}{l}\text { aaaabcccdefffefgefghi } \\
\text { jklmnoooo }\end{array}$ & 30 & 15 & 15 & 23 & 19.4 & 36.31 \\
\hline $\begin{array}{l}\text { aaabbabccbcbbbcdde } \\
\text { efghijjjjjjj }\end{array}$ & 30 & 10 & 20 & 23 & 20.6 & 37.89 \\
\hline $\begin{array}{l}\text { abababababcdceabcde } \\
\text { deaaaaaaabc }\end{array}$ & 30 & 5 & 25 & 36.7 & 16.67 & 47 \\
\hline
\end{tabular}

Tabel 7 Input Message

\begin{tabular}{|l|l|l|l|l|}
\hline \multicolumn{5}{|c|}{ Message that has many repeating character pairs } \\
\hline Input Message & $\begin{array}{l}\text { Sum of } \\
\text { Characters }\end{array}$ & $\begin{array}{l}\text { LZW } \\
\text { Compression } \\
\text { Ratio(\%) }\end{array}$ & $\begin{array}{l}\text { Huffman } \\
\text { Compression } \\
\text { Ratio (\%) }\end{array}$ & $\begin{array}{l}\text { LZW } \\
\text { Huffman } \\
\text { Compression } \\
\text { Ratio (\%) }\end{array}$ \\
\hline ular lari lurus & 15 & 13.02 & 20.63 & 31.51 \\
\hline saya suka susu sapi & 19 & 21.26 & 21.26 & 35.06 \\
\hline eleven benevolent elephants & 27 & 18.69 & 20 & 33.33 \\
\hline $\begin{array}{l}\text { freezy breeze made these } \\
\text { three trees freeze }\end{array}$ & 43 & 30.07 & 24.24 & 43.82 \\
\hline $\begin{array}{l}\text { can you can a can as a canner } \\
\text { can can a can? }\end{array}$ & 44 & 38.65 & 18.69 & 48.45 \\
\hline
\end{tabular}


International Journal of Computer Networks \& Communications (IJCNC) Vol.7, No.2, March 2015

Table8 Processing Time

\begin{tabular}{|c|c|c|c|}
\hline \multicolumn{4}{|c|}{ Input message with difference in the sum of characters and symbol 0} \\
\hline No & Input Message Input & $\begin{array}{l}\text { Time to create } \\
\text { message(second) }\end{array}$ & $\begin{array}{l}\text { Time to read } \\
\text { message (second) }\end{array}$ \\
\hline 1 & detik & 0.04 & 0.042 \\
\hline 2 & abcdefghij & 0.052 & 0.055 \\
\hline 3 & detik0123456789 & 0.06 & 0.058 \\
\hline 4 & $! @ \# \$ \% \wedge \& *()_{-}-+=: ;, .<>$ & 0.063 & 0.062 \\
\hline 5 & abcdefghijklmnopqrst!@\#\$\% & 0.064 & 0.064 \\
\hline \multicolumn{4}{|c|}{ Input message with different in the sum of characters and different symbols } \\
\hline No & Input Message Input & $\begin{array}{l}\text { Time to create } \\
\text { message(second) }\end{array}$ & $\begin{array}{c}\text { Time to read } \\
\text { message (second) }\end{array}$ \\
\hline 6 & aabbbbcdefghijklmnopqrstuvwxy & 0.049 & 0.05 \\
\hline 7 & aaaabcbcbcddddefghijklmnopqrst & 0.05 & 0.048 \\
\hline 8 & aaaabcccdefffefgefghijklmnoooo & 0.045 & 0.042 \\
\hline 9 & aaabbabccbcbbbcddeefghijjjjjjj & 0.048 & 0.05 \\
\hline 10 & abababababcdceabcdedeaaaaaaabc & 0.056 & 0.059 \\
\hline \multicolumn{4}{|c|}{ Input message with repeating character pairs } \\
\hline No & Input Message Input & $\begin{array}{l}\text { Time to create } \\
\text { message(second) }\end{array}$ & $\begin{array}{l}\text { Time to read } \\
\text { message (second) }\end{array}$ \\
\hline 1 & ular lari lurus & 0.038 & 0.04 \\
\hline 2 & saya suka susu sapi & 0.038 & 0.037 \\
\hline 3 & eleven benevolent elephants & 0.055 & 0.05 \\
\hline 4 & $\begin{array}{l}\text { freezy breeze made these three trees } \\
\text { freeze }\end{array}$ & 0.061 & 0.066 \\
\hline 5 & $\begin{array}{l}\text { can you can a can as a canner can can a } \\
\text { can? }\end{array}$ & 0.065 & 0.064 \\
\hline
\end{tabular}

